"No ears allowed?"

\title{
An Anthropological Exploration of the International Symbol of Deafness
}

\author{
Robyn D. Swannack ${ }^{1}$ and Helen Macdonald ${ }^{2}$ \\ swnrob006@myuct.ac.za ${ }^{1}$ \\ helen.macdonald@uct.ac.za ${ }^{2}$ ORCID: orcid.org/0000-0002-0708-4302
}

Supervisor: Helen Macdonald

Department: African and Gender Studies, Anthropology and Linguistics

\begin{abstract}
Symbols shape how social actors experience, feel and make meaning of their everyday life and social interactions. When we see a symbol, our brain processes it and denotes its meaning. Some symbols have obvious and clear meaning; others are vague, unclear and ambiguous. In this paper, I interrogate the international symbol of deafness / hard of hearing. On one level, the international symbol of deafness/hard of hearing acts as a key summarising symbol. Here it intends to represent the deaf community. However, through interviews with the Deaf community, their friends, parents, interpreters and CODA (Children of Deaf Adults) I show that the symbol operates more as an elaborating symbol, by fitting complex and possibly indistinguishable beliefs, practices, concepts and emotions into a workable framework.
\end{abstract}

Keywords: Anthropology, symbols, deafness 
http://journals.uct.ac.za/index.php/UR

DOI 10.15641/ur-at-uct.v1i1.35 
“No ears allowed?"

An Anthropological Exploration of the International Symbol of Deafness ${ }^{1}$

\section{Introduction:}

A symbol is defined as 'anything that carries a particular meaning recognized by people who share a culture' (Macionis and Plummer, 2005:107). Symbols are also interpreted in a way that shapes people and lives; to express the contents and situations of everyday life. Symbols may shape how social actors see, feel and think through the impacts and perspectives of the outcomes through their everyday life and social interactions. When we see a symbol, our brain processes it and denotes its meaning. Some symbols have obvious and clear meaning; others are vague, unclear and ambiguous such as the one I present here. In this essay, I interrogate the international symbol of deafness / hard of hearing (see figure 1) - a key symbol which originates from Sign Language. As a sign, this key symbol indicates an individual(s) who is deaf, hard of hearing, or having some degrees of hearing loss. In addition, this symbolic representation of the deaf community has intended to communicate an awareness of deaf people and their different needs for access (Loss, 2014).

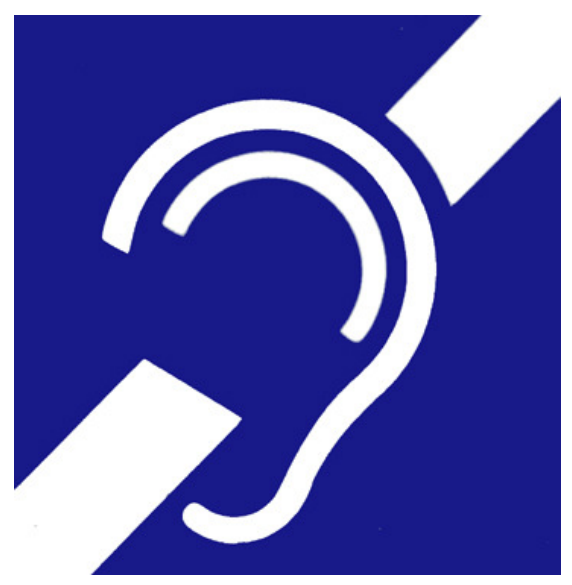

Figure 1: The international symbol of deafness or hard of hearing

\footnotetext{
${ }^{1}$ This essay was submitted for Belief and Symbolism, a second year Anthropology course in 2014. I am grateful for the assistance of Ms Miriam Waltz (tutor), Ms Yusra Price (mentor) and Dr Helen Macdonald (course convener).
} 
Sherry Ortner's seminal essay laid out an analysis for the recognition and operation of 'key symbols', not to be studied in and of themselves, but for what they can reveal about social processes (1973). The focus of interest is not why a symbol is key; it is only a signal that the symbol is playing some key role in relation to other elements. 'Every culture' she argued, 'has certain key elements which, in an ill-defined way, are crucial to its distinctive organizations' (1973: 1338). For Ortner, these key elements were a 'jumble' of 'things and abstractions, nouns and verbs, single items and whole events' (ibid: 1339). Programmatically laying out an analysis for recognising and using key symbols, Ortner defined two kinds of key symbols on an ideal-type continuum: 'summarising' and 'elaborating'. Ortner was careful to point out that her typology was a heuristic concept rather than a precise reflection of distinct and distinguishable kinds of symbols. Paying heed to this warning, I draw on her model as a framework within which the complexities of an unfamiliar system of cultural symbols may be sorted out. The use of key symbols here should not be viewed as deterministic or overly constraining.

In this paper I discuss whether the international symbol of deafness or hard of hearing is a key symbol and for whom. For Ortner, a summarising symbol, not surprisingly, 'sums up, expresses and represents' several complete ideas into one symbol or sign that the individual perceives, that is, it comes to 'stand for' the system as a whole (1973: 1340). I argue that the international symbol of deafness or hard of hearing intends to act as a summarising symbol but fails in 'crystallising commitment' to it. According to Ortner, a summarising symbol speaks to a level of emotional response, in that it 'focuses power, draws together, intensifies thereby catalyzing impact' on an individual (Ortner 1973: 1342). In short, summarising symbols result in a 'crystallisation of commitment' to a singular meaning of the symbol. Using ethnographic research methods I show that this symbol is contested by the Deaf community, their friends, parents, interpreters and CODA (Children of Deaf Adults). In fact, I show that the symbol operates more as an elaborating symbol. Elaborating symbols succeed by fitting complex and possibly indistinguishable beliefs, practices, concepts and emotions into a workable framework. When a symbol comes to stand in for this complexity, an individual can communicate their ideas to others more 
effectively. Elaborating symbols help to sort, categorise and make sense of experience.

\section{Representing the Deaf Community:}

Some symbols are representative of a particular group. Identity is created when one takes into account the sign's symbolic aspect; it plays a fundamental role in the process of creating identity and to understand community. In this case, the symbol represents the deaf community through an image. Geertz (1973) says that a symbol is one thing, but people's perception of it is another. Among the Deaf community there are two distinct approaches in defining deafness. There is a medical approach and a social approach. The medical approach defines Deaf people as a medical condition, something that needs to be fixed. In contrast, the social approach defines Deaf people a group of people that have a community, culture and a language and therefore deafness does not need fixing. Deaf people have their own identities, including participating in the life of the Deaf community and a visual language of their own. The Deaf community is rich in its language, its traditions and its history and 'distinct folk language and literary tradition, social, sport, recreational institutions, schools and education' (Deaf Culture, 2014). Sign Language has aided the deaf community to communicate with hearing and non-hearing others. It is important to note that while the international symbol of deafness is used as a key symbol by the international deaf community, there is no universal form of Sign Language.

I now turn to discuss my research design and findings.

\section{Research Design}

For this project I interviewed people in the Deaf community to gather their opinions and criticisms on the symbol. I interviewed some of the participants through the use of social network sites, such as Facebook \& FaceTime (for international deaf members) and through email (for participants in provinces besides Western Cape). I managed to interview 9 participants face-to-face at a social event and at University 
of Cape Town. Participants ranged from hard of hearing (the term is often used to describe people with any degree of hearing loss, from mild to profound and to describe those who do not participate in the deaf world), CODA (Children of Deaf Adults), interpreters and friends of the deaf.

\section{Findings: A Heavily Contested Symbol}

The symbol for deafness is intended to act as a summarising key symbol. The universal use of this symbol for deafness has various contexts: (1) it is being used to show that there are Deaf people in such places; (2) it is used to define Deafness; and (3) it is being used for medical interpretation. My findings show that there are national differences in the symbol as 'summarising'. Outside of South Africa, symbol awareness is greater, especially in America and Australia where they have passed laws recognising their respective sign language as one of the official national languages.

My thoughts on this symbol are GREAT! This is very useful for the travellers in foreign countries that do not read or speak English. I was in Berlin. This symbol was on the building, so I went inside and met international deaf people.

Deaf South African living in America, age 55

I find nothing wrong with this symbol. For me it means awareness for hearing people, that there are deaf people around.

Deaf South African, age 29

This symbol is commonly used in Australia, and l've seen it at almost every event/meeting/deaf company. I find the symbol acceptable depending on its interpretation. That is, is it used to 
let people know that there are deaf people in such areas, or is it being used to define deaf people? Thus, if it is being used to let people know, it's very acceptable.

Hearing Australian, age 25

I do not have a problem with this symbol as this is an internationally recognized sign for "No Hear" and is often used to represent people with disabilities. Some Deaf people dislike the symbol as the symbol brings attention to their 'deficiency' not their language and ability which is Sign Language.

Deaf American, age 47

South African Sign Language is not an official language in South Africa, and that has led to limited awareness, in addition to the multiple cultures, ethnic groups and languages found in the country. There is a lack of awareness, combined with the lack of people who are Deaf and the lack of interaction with those who are Deaf.

I feel as if this symbol is semi-okay as with the way people are today it could've been more crudely done (i.e. like a no smoking sign except with an ear - which I would find super offensive). I do find that since I didn't actually know what the symbol was, until you explained it, that MORE people should be made aware of it. Especially people who aren't deaf, since the majority don't come into contact with deaf people or take the time to try and communicate with deaf people.

Hearing South African, age 21

In order for hearing people to comprehend the international symbol of deafness (Loss, 2014), they need to understand the culture and the community of deaf people and understand the symbol in full. Does the sign have to be universal? If we base it on sign language, is 'Deaf' in sign language the same in every country? Since each 
country has their own dialect of sign language so to speak, how was a universal sign/symbol developed in such differing circumstances?

The quotes above, however, point to ways in which the symbol carries alternative meanings. For many, the symbol was considered an unacceptable use of sign to identify or describe deafness.

My first thought was "Why are you doing this? Are you treating me like I must block my ears even if I could hear little enough? It seems like you're saying 'Please, it's okay. Remember what this symbol is for. It's for hearing people to be aware" You seem to have upset me because you seem cut my ears off like this symbol."

Deaf South African, Age 27

I am very against this symbol. It indicates me that the ear is blocking and deafness is a sign. What does it supposed to mean? Deafness affected deaf people that they cannot do anything because they just cannot hear? The way how deafness is shown by this symbol is discrimination. I feel it is abusing our Deaf culture. We need to be treated equally, and use our hands as a symbol of sign language would be much better. Deaf culture is mostly about visual language which is used hands for sign language. What's wrong with using hands? Sign language is an exquisite language.

Deaf South African, Age 23 I always dislike this symbol. It's not relevant to our deaf community. We are using sign language e.g. hand symbols are more relevant. But this symbol is good for the loop for hard of hearing people?

Deaf Australian, age 50 
These remarks of some people in the Deaf community can be interpreted into various meanings and perspectives of the symbol - that is, it's elaborating function. For the third speaker, the symbol is more culturally acceptable for the $100 p^{2}$, the hearing aid for hard of hearing people ${ }^{3}$, because their community and culture is not rich in Deafness, and the language of Sign Language. The comments above from two young South African deaf members express how the sign/symbol indicates that their ears are "blocked". The forward slash on a sign or symbol is commonly accepted as a sign of prohibition i.e.: you are prohibited from doing the activity/thing pictured in the image. The sign poses an ambiguity in that the forward slash represents prohibition, however in this case, the forward slash represents 'a lack of'. So what is this sign actually conveying? It could be a variety of things: ears do not show hearing loss. After all, my ears look the same as any Deaf or hearing person. So, does the sign mean no ears allowed? No hearing people allowed? No Deaf people allowed? Deaf people do not have access? Importantly, the forward slash symbol is not used to represent are differently abled bodies, such as the blind or wheelchair users (see figure 2).

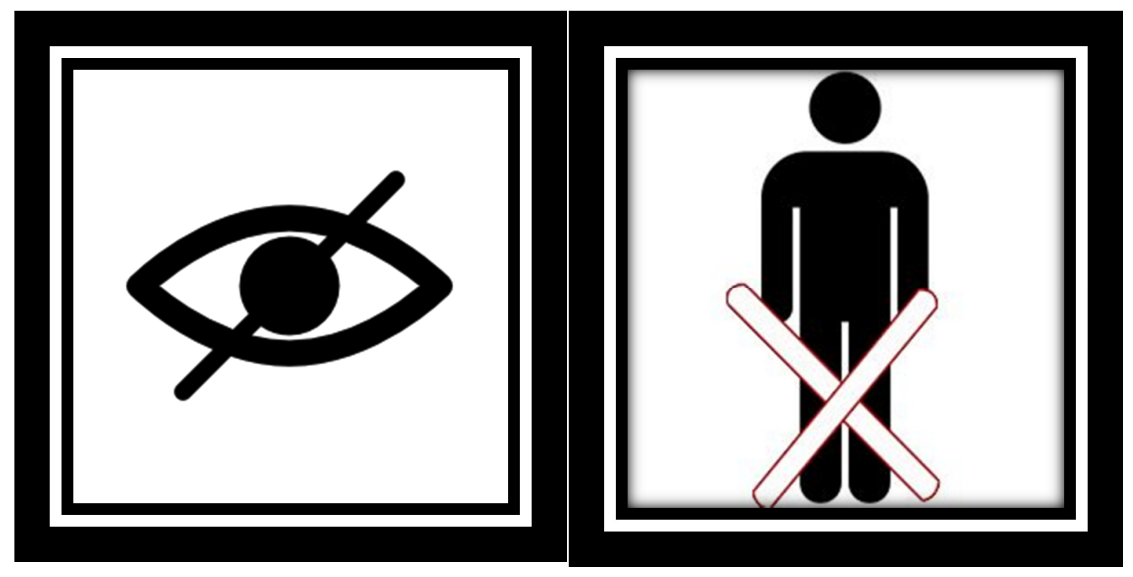

Figure 2: Alternative symbols to express blindness or a wheelchair user

The difference between the no smoking symbol and the deaf symbol is that with the former, there's an inanimate object that represents the act of smoking and not

\footnotetext{
${ }^{2}$ An induction or inductive loop is an electromagnetic communication or detection system which uses a moving magnet to induce an electrical current in a nearby wire. A common modern use for induction loops is to provide hearing assistance to hearing-aid users.

${ }^{3}$ The general definition of "Hard of Hearing" is a group of people who is not involved in the Deaf community and culture, those who do not speak Sign Language.
} 
necessarily the smoker. The latter symbol however, uses the actual ear and therefore represents the people themselves. This is why there is an implication that the ear and by extension the person is prohibited. It could be that what is intended to be represented and what is actually presented are two different things and this is where the problem lies.

Deaf people do not focus their deafness on the fact they cannot hear, but on the basis of their culture, where sign language is a factor of the culture. Many of those I interviewed felt that a sign that represents deafness should be in a visual image taken from sign language. The use of social interpretation of the symbol would be the use of hands, instead of ears, in particular the $U$ shape (see figure 3 ) over the ear. This is the recognized sign for "Deaf" in South Africa (and many other countries) instead of a line over the ear. If the symbol is something of hands or a $U$ shape (see figure 3) over the ear, would people understand?

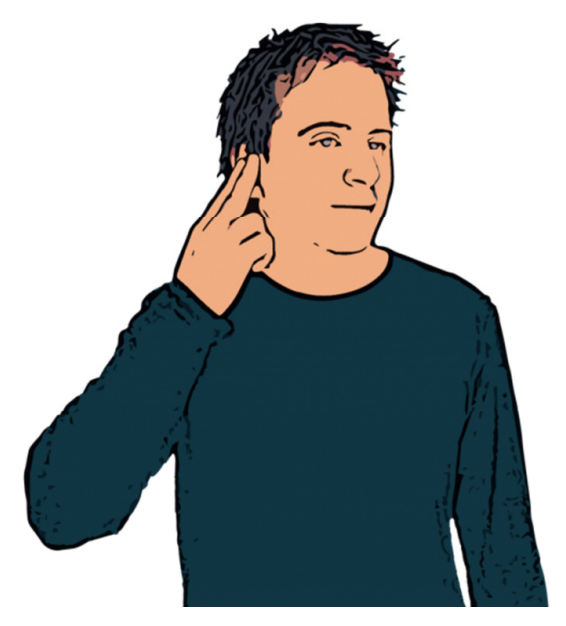

Figure 3: An alternative international symbol of deafness or hard of hearing

The responses from the members of the Deaf community show the multiple meanings the symbol carries, however their interpretations largely overlook that the symbol is intended to convey meaning for hearing people instead of the Deaf community, particularly in terms of awareness. So how do hearing people respond to the symbol? I found that responses vary according to their experiences and knowledge on deafness, and on their interaction with deaf people. 
I do not like it as it focuses on what the Deaf cannot do as opposed to what they can do. Although not being able to hear is defining characteristic of deafness so is sign language and so I would prefer that there is a focus on the positive and not the medical diagnosis in designing a symbol for deafness. I find it unacceptable, as it defines a deaf person in negative terms in the same way that black people were labelled non-white under apartheid. It defines a deaf person by comparing them to the "norm" of hearing and saying how they lack.

Hearing British, age 38

When I first look at it, it makes me think: "No deaf people allowed" for a spilt second. It also reminds me of those "No smoking" signs. But it might also mean "deaf people are present here." At the same time, it looks like it says "no hearing allowed." It's ambiguous in a way.

Hearing South African, age 21

The remarks on how the symbol labels deaf people in the ways it labels black people as the "non-whites" during the apartheid, with its negative terms has an efficient outcome of the interpretation of a culture. The person's quote spoke about the 'norm' and this is very crucial. The norm is hearing and so deaf is opposed to this. In the apartheid era, the white people were the norm whereas black people were understood as 'lesser than' white.

\section{Concluding Comments:}

The symbol is a challenge to both the deaf world, and the hearing world. Internationally, the symbol acts as a key summarising symbol to represent deafness. In South Africa, where awareness of the Deaf is limited, the symbol is criticized more heavily than overseas. This is most likely a result of the multiple languages spoken in South Africa and the fact that sign language is not an official language of South Africa. 
My research among the hearing showed that they immediately understood that the symbol represents hearing loss, where hearing is positioned as the norm. This notion of 'hearing loss' emphasised deficit and thus these research participants tended to view deafness as a medical condition. Those people who viewed deafness as a medical condition understood and approved of the symbol.

The Deaf and others I interviewed viewed the Deaf as a community and with a culture and its own rich visual language knowledge. For this group, the symbol of the deaf posed multiple confusions and contestations. For many it provoked a sense of prohibition of ears rather than a lack of hearing. Therefore the impression of the sign has multiple meanings and this can be problematic. Furthermore, in light of this ambiguity, the sign/symbol is meant to alert those who can hear to those who cannot hear, however the awareness of the deaf community stays minimal. 


\section{References:}

Deaf Culture. 2014. Comparative Chart: Deaf and Ethnic Cultures. [online] Available at: http://www.deafculture.com/ethnic_culture/ [Accessed 21 Aug. 2014]

Geertz, Clifford. 1973. "The Wink," extract from The Interpretation of Cultures.

Fontana Press. Pp.6-7

Loss, T. 2014. The International Symbol of Access for Hearing Loss. [online] Available at: http://www.healthyhearing.com/content/faqs/Technology/T-coils/31145International-symbol-access-for [Accessed 20 Aug. 2014]

Macionis, J. and Plummer, K. 2005. Sociology. $1^{\text {st }}$ ed. Harlow: Pearson Prentice Hall Press.

Ortner, Sherry B. 1979. On Key Symbols. In William Lessa (ed.) Reader in Comparative Religion: An Anthropological Approach. New York: Harper and Row.

Pp. $92-98$ 